\title{
Quantitative genetics of floral traits in a gynodioecious wild strawberry Fragaria virginiana: implications for the independent evolution of female and hermaphrodite floral phenotypes
}

\author{
TIA-LYNN ASHMAN \\ Department of Biological Sciences, University of Pittsburgh, Pittsburgh, PA 15260, U.S.A.
}

\begin{abstract}
The independent evolution of floral phenotype is an important part of the process of gender specialization during the evolution of dioecy from hermaphroditism. However, we have little information on the genetic variation of floral traits in species with separate genders. Gynodioecious species (co-occurrence of females and hermaphrodites) have a breeding system intermediate between hermaphroditism and complete separation of the sexes (dioecy) and thus can provide insight into the genetic architecture underlying floral phenotype with respect to both primary (stamens and carpels) and secondary (petals) sexual traits. I used a nested breeding design to examine the potential for response to selection on floral traits and to examine whether this response would be similar in the two sex morphs of gynodioecious Fragaria virginiana. There was significant genetic variation underlying all floral traits, although narrow-sense heritabilities (ranging from -0.25 to 0.44 ) were, in most cases, much lower than broad-sense ones (ranging from 0.28 to 1.53). Moreover, the sex morphs differed significantly in their heritabilities for shared traits, such as stamen length, and showed a tendency towards differing significantly in others, like carpel number and petal length. In addition, correlations between the sex morphs for these traits (ranging from 0.41 to 0.58 ) were significantly greater than 0 , but less than 1 . These results indicate that greater sexual dimorphism could evolve in this population of $F$. virginiana, even if selection on these traits is not divergent. However, strong developmental integration of floral traits (e.g. stamen length and petal length) and high levels of nonadditive genetic variance may represent barriers to the evolution of complete sexual dimorphism.
\end{abstract}

Keywords: floral traits, Fragaria virginiana, genetic correlation, gynodioecy, heritability, sexual dimorphism.

\section{Introduction}

Recently the evolution of sex specialization in plants has been viewed from a quantitative genetics perspective (e.g. Morgan, 1992). A quantitative genetics approach allows for simultaneous evaluation of modifications in many reproductive traits that often accompany gender separation and specialization in plants (Morgan, 1992). In addition, because this approach provides an explicit methodology for partitioning reproductive trait evolution into its selective and genetic components (e.g. Arnold, 1983; Morgan,

Correspondence. E-mail: tia1+@pitt.edu
1992) it can give considerable insight into how these combine to determine the evolutionary trajectories of the sexual phenotypes.

Two quantitative genetic models explore sexual divergence directly. Lande (1980) derived expressions for selection acting on separate male and female fertility optima in a dioecious species, and showed that when heritabilities are equal in the sexes, the response of a trait to sex-differential selection is determined not only by the degree of additive genetic (co)variation present within each sex, but also the degree of genetic correlation between the sexes. Specifically, he concluded that a high additive genetic correlation between the sexes can constrain the independent evolution of a trait that is under sex-differential selection (Lande, 1980). Cheverud 
et al. (1985), on the other hand, have shown that sexual dimorphism can evolve in the absence of sex-differential selection, as long as there is dimorphism in the genetic or phenotypic variance parameters. Under conditions of variance dimorphism, a high between-sex correlation can actually facilitate the evolution of sexual dimorphism. Furthermore, Cheverud et al. (1985) conclude that sexual dimorphism can evolve faster when differential selection and variance dimorphism favour the same direction of response.

Sexual dimorphism in floral traits, including primary (stamens and ovaries) and secondary (petals) sexual organs (e.g. Ashman, 1994; Delph et al., 1996) is commonly found in plants with separate genders. Although theoretical and empirical work suggests that this floral dimorphism is brought about by sexdifferential selection (e.g. Bell, 1985; Conner et al., 1996; Delph et al., 1996), we have little knowledge of the genetic architecture underlying floral phenotype in sexually di- or polymorphic species [dioecious Silene latifolia (Meagher, 1999) and tristylous Lythrum salicaria (O'Neil \& Schmitt, 1993)]. Thus, our ability to evaluate the potential for sex-differential selection to bring about sexual divergence in plant floral phenotype remains limited.

Species that show incomplete separation of the sexes, or those with intermediate breeding systems, such as gynodioecy (co-occurrence of female and hermaphrodite morphs), provide an important opportunity to study the dynamics of reproductive character evolution with respect to both primary and secondary sexual traits, and to gain insight into how the current genetic architecture may influence sexual dimorphism in floral phenotype during the separation of the sexes. Here, I examine the potential for independent evolution of primary and secondary sexual traits in gynodioecious Fragaria virginiana by pursuing the following specific objectives: (i) determine the heritability of floral traits; (ii) determine the degree of genetic correlation between floral traits within each sexual morph, as well as between the sexual morphs; (iii) determine if there is sexual dimorphism in these genetic parameters.

\section{Materials and methods}

\section{Study organism}

Fragaria virginiana (Rosaceae), the Virginian wild strawberry, is a creeping perennial herb that is native to eastern North America (Staudt, 1989) and commonly grows in meadows, old fields, and along road and forest edges. Reproduction is by sexually produced seed or vegetatively produced clones. Flowers are borne on loose di- or plieochasial inflorescences (Ashman \& Hitchens, in press) and those of both sex morphs contain 20-30 stamens and a fleshy receptacle that supports numerous uniovulate carpels. Stamens of females are vestigial, white and devoid of pollen (Valleau, 1923). Receptacles and carpels of hermaphrodites are well developed, but often fail to set fruit, even under optimal conditions (Staudt, 1989; Ashman, 1999). Females produce the majority of the seed in populations in NW Pennsylvania (Ashman, 1999). Sex determination is under nuclear control, with male sterility (femaleness) dominant to male fertility (Valleau, 1923; Ahmadi \& Bringhurst, 1989). Although $F$. virginiana has a polyploid origin, it currently behaves cytogenetically like a diploid (Bringhurst, 1990).

Fragaria virginiana is pollinated by small native bees, flies and ants (Ashman, in press). Bees, the most abundant and effective pollinator class, selectively visit flowers with longer petals, more nectar and a pollen reward (Ashman, in press). In addition, there is evidence for sex-differential selection on petal and stamen length: pollen receipt by females is influenced more by petal than stamen length, whereas pollen removal from hermaphrodites is influenced more by stamen than petal length (Ashman, in press).

\section{Crosses and cultivation}

Fruits (one per plant) were collected from a recently established population of $F$. virginiana in an abandoned hay field in Crawford Co., PA. One seed per fruit (maternal family) was randomly chosen to form the parental generation which was cultivated in a greenhouse at the University of Pittsburgh. The crossing design involved two female 'dams' nested within each of 42 hermaphrodite 'sires', yielding 84 maternal full-sib families nested within 42 paternal half-sib families. Approximately 10 flowers per female were hand-pollinated, and 39 seeds per maternal full-sib family were planted in three blocks of a randomized design. Germination averaged $70 \%$. Up to seven seedlings per block were transplanted into $7.62 \mathrm{~cm}$ square pots filled with Fafard no. 4 soil and grown in the glasshouse for four months, receiving $100 \mu \mathrm{g} \mathrm{g}^{-1}$ 20:20:20 Plantex fertilizer twice a month. All plants received a two-month chilling period $\left(4^{\circ} \mathrm{C}\right)$ in a growth chamber, prior to being returned to a glasshouse with supplemental heating and lighting. During flowering, plants were fertilized at a rate of $50 \mu \mathrm{g} \mathrm{g}^{-1}$ twice a month. Because of either poor germination, survival or flowering, maternal full-sib family sizes ranged from 20 to two with an average of 12 progeny per mother. 


\section{Scoring of floral characters}

The first flower to open per plant was scored in the following ways on the first day of anthesis: (i) if the flower was hermaphrodite, the longest stamen was measured to the nearest $0.01 \mathrm{~mm}$ using digital calipers and the indehiscent anther sacs from all stamens were collected in a microcentrifuge tube for later pollen counting; (ii) if the flower was female, it was simply marked. On the second day of anthesis, the longest petal on flowers of both sex morphs was measured with digital calipers, the flowers were harvested, and carpels were counted with the aid of a dissecting microscope. At this time, if the flower was female the length of the longest stamen was measured using an eyepiece micrometer. Harvested flowers were dried for $24 \mathrm{~h}$ at $35^{\circ} \mathrm{C}$, and weighed to the nearest $0.1 \mu \mathrm{g}$ on a Cahn microbalance (Cahn C-31). Total floral biomass was determined for up to six female and six hermaphrodite progeny per maternal full-sib family. Biomass of hermaphrodite flowers was adjusted to account for the weight of removed anther sacs. Petal length measurements and anther collections were also taken on the third flower to open per plant, and these were averaged with measurements taken on the first flower for use in the analyses described below. Flower number per plant was recorded at the end of flowering. The number of pollen grains per flower was scored using an Elzone particle counter (Elzone 280PC) following the methods outlined in Ashman (1999).

\section{Estimation of genetic variances and heritabilities}

Total and additive genetic variances, coefficients of variation, and broad- and narrow-sense heritabilities were estimated for the progeny generation by sex morph. Type I mean squares and coefficients for expected mean squares were calculated from a nested analysis of variance using procedure GLM in SAS 6.12 (SAS, 1989). Variance components and heritabilities were estimated following the methods described in Lynch \& Walsh (1998). Significant sire and dam effects in the nested ANOVA indicate significant additive and broad-sense genetic variances, respectively, and although confidence limits for heritabilities derived from these may overlap zero (see below), significant heritabilities may still be assumed (Roff, 1997). Additive genetic variance was estimated as four times the sire variance component, and was used to calculate the narrow-sense heritability as the proportion of the total phenotypic variance, and the additive genetic coefficient of variation $\left(C V_{\mathrm{a}}\right)=100 \sqrt{V_{\mathrm{a}} / \overline{\mathrm{x}}}$, where $\overline{\mathrm{x}}$ is the phenotypic mean value of the trait. Likewise, four times the dam variance component was used to calculate broad- sense heritability and total genetic coefficient of variation $\left(C V_{\mathrm{g}}\right)$ based on full-sib progeny. The dam component of variance in a nested design includes all the variance associated with dominance and maternal effects, as well as additive effects, but can be of value in providing information on the relative significance of these components of variance (Lynch \& Walsh, 1998). A jackknife resampling procedure was used to estimate standard errors (e.g. Roff, 1997) of heritability estimates. In some cases, negative estimates of variance components were obtained. These are commonly attributed to sampling error, and nested mating designs like the one used here (i.e. two dams/sire) can have a high probability of producing negative variances, and thus, heritabilities outside their valid ranges (Bridges \& Knapp, 1987). As negative estimates are likely to suggest that the actual variance is quite small (i.e. close to zero), heritabilities based on these are often reported as zero. However, Lynch \& Walsh (1998) advocate reporting actual values obtained, and this was followed here for both very low (negative) as well as high (greater than 1) $h^{2}$ estimates. Analyses were carried out on both natural and natural log scales. Only the results for variables on their natural scale are presented because the conclusions were unaltered by transformation, and estimates based on untransformed variables are preferable when one's interest is to apply these to models of selection (Houle, 1992).

\section{Estimation of genetic and phenotypic correlations}

Genetic correlations were calculated between traits within each sex morph and between the two sex morphs using the family structured progeny data. Pearson product-moment correlations were performed on paternal half-sib family means that were obtained by first averaging same-sexed progeny from each dam and then averaging over both dams per sire. Significance of correlations was determined by $t$-tests. However, to provide an estimate of the variance around individual correlation coefficients, standard errors were estimated by a jackknife resampling procedure (e.g. Roff, 1997). One-tailed $t$-tests were used to determine if correlations between homologous traits in the sex morphs were different from 1. Phenotypic correlations among traits within each sex morph were also calculated for comparative purposes.

\section{Comparisons between the sex morphs}

Phenotypic means for floral traits were compared using $t$-tests, whereas variance ratio $F$-tests were used to compare phenotypic variances and coefficients of phenotypic variation between the sex morphs. 
Table 1 Phenotypic means \pm SE, variances and coefficients of variation for floral traits in female and hermaphrodite Fragaria virginiana $\left(N_{\mathrm{F}, \mathrm{H}}=486,522\right.$ for all traits, except flower biomass where $\left.N_{\mathrm{F}, \mathrm{H}}=381,401\right)$. Means were compared by $t$-tests, phenotypic variances and coefficients of variation by variance ratio $F$-tests

\begin{tabular}{lccc}
\hline Trait & Females & Hermaphrodites & Test \\
\hline Mean \pm SE & & & $t$-test \\
Flower number & $9.1 \pm 0.2$ & $10.0 \pm 0.2$ & $4.39^{* * * * *}$ \\
Flower biomass (mg) & $10.25 \pm 0.13$ & $18.07 \pm 0.18$ & $34.49^{* * * * *}$ \\
Carpel number & $101.1 \pm 0.9$ & $99.7 \pm 0.9$ & 1.07 \\
Petal length $(\mathrm{cm})$ & $6.86 \pm 0.05$ & $9.93 \pm 0.05$ & $43.50^{* * * *}$ \\
Stamen length $(\mathrm{cm})$ & $1.66 \pm 0.02$ & $4.55 \pm 0.03$ & $90.02^{* * * * *}$ \\
Pollen number & $-\dagger$ & $300905 \pm 2584$ & - \\
Phenotypic variance & & & $F$-test \\
Flower number & 11.12 & 14.79 & $1.33^{* * * *}$ \\
Flower biomass & 6.839 & 13.376 & $1.96^{* * * *}$ \\
Carpel number & 452.89 & 442.71 & 1.02 \\
Petal length & 0.9927 & 1.5333 & $1.54^{* * * *}$ \\
Stamen length & 0.1478 & 0.384 & $2.57^{* * * *}$ \\
Pollen number & - & $3.795 \times 10^{9}$ & - \\
Coefficient of phenotypic variation & & & $F$-test \\
Flower number & 36.85 & 38.29 & 1.01 \\
Flower biomass & 25.50 & 20.24 & $1.44^{* * *}$ \\
Carpel number & 21.05 & 21.11 & 1.01 \\
Petal length & 14.52 & 12.47 & $1.40^{* * * *}$ \\
Stamen length & 23.15 & 13.54 & $2.70^{* * * *}$ \\
Pollen number & - & 20.47 & - \\
\hline
\end{tabular}

$\dagger$ Only hermaphrodites produce pollen.

${ }^{*} P<0.05 ;{ }^{* *} P<0.01 ;{ }^{* * *} P<0.001 ; * * * * P<0.0001$.

Randomization tests (e.g. Roff, 1997) were used to determine if heritabilities and genetic correlations were significantly different between the sex morphs, because randomization tests do not rely on the assumptions of equal variances or normality, and are more powerful than $t$-tests based on jackknife-derived standard errors (J. Lawrence \& T.-L. Ashman, unpubl. data). For these comparisons the nested structure of the data was retained, and progeny of each dam were reassigned at random to either 'female' or 'hermaphrodite' subgroups irrespective of their actual sexual identity; then the difference between the heritabilities or genetic correlations was calculated. The probability of obtaining a difference as high or higher than the one observed was determined from 10000 resampled data sets.

\section{Results}

\section{Sexual dimorphism in floral traits}

Phenotypic means and variances for all floral traits, except carpel number, were significantly larger in hermaphrodites than in females (Table 1). Heterogeneity of variances may, in part, be attributable to scaling effects brought about by the larger means for floral traits of hermaphrodites, but significant heterogeneity remained when the coefficients of variation were compared (Table 1).

\section{Heritabilities of floral traits in hermaphrodites and females}

Broad-sense heritabilities were generally strong and significant, whereas narrow-sense heritabilities were generally low and most were not distinguishable from zero (Table 2). Notable exceptions, however, were narrow-sense heritabilities for carpel number in females $\left(h_{\mathrm{N}}^{2}=0.38\right)$, and stamen length in hermaphrodites $\left(h_{\mathrm{N}}^{2}=0.44\right)$. Evolvabilities $\left(C V_{\mathrm{g}}\right.$ and $\left.C V_{\mathrm{a}}\right)$ showed patterns similar to those of the heritabilities.

Randomization tests revealed that the heritability of stamen length was significantly different in the two sex morphs (both $h_{\mathrm{N}}^{2}$ and $h_{\mathrm{B}}^{2}: P<0.001$ ), and the heritability of carpel number $\left(h_{\mathrm{N}}^{2}, h_{\mathrm{B}}^{2}: P=0.06,0.09\right)$ and petal length $\left(h_{\mathrm{N}}^{2}: P=0.08\right)$ were marginally significantly different between the sex morphs. These differences 
Table 2 Narrow- and broad-sense heritabilities $\left(h_{\mathrm{N}}^{2}, h_{\mathrm{B}}^{2}\right.$, respectively) (SE), and additive and total genetic coefficients of variation for female and hermaphrodite progeny of Fragaria virginiana from a nested breeding design

\begin{tabular}{|c|c|c|c|c|c|c|c|c|c|c|c|c|}
\hline \multirow[b]{2}{*}{ Trait } & \multicolumn{6}{|c|}{ Females } & \multicolumn{6}{|c|}{ Hermaphrodites } \\
\hline & $h_{\mathrm{N}}^{2}$ & $h_{\mathrm{B}}^{2}$ & $V_{\mathrm{a}}$ & $V_{\mathrm{g}}$ & $C V_{\mathrm{a}}$ & $C V_{\mathrm{g}}$ & $h_{\mathrm{N}}^{2}$ & $h_{\mathrm{B}}^{2}$ & $V_{\mathrm{a}}$ & $V_{\mathrm{g}}$ & $C V_{\mathrm{a}}$ & $C V_{\mathrm{g}}$ \\
\hline Flower number & $\begin{array}{c}0.13 \\
(0.17)\end{array}$ & $\begin{array}{c}0.32 * \\
(0.28)\end{array}$ & 1.4614 & 3.5982 & 13.35 & 20.96 & $\begin{array}{c}0.03 \\
(0.19)\end{array}$ & $\begin{array}{l}0.52 * * \\
(0.42)\end{array}$ & 0.4622 & 7.7540 & 6.77 & 27.74 \\
\hline Flower biomass & $\begin{array}{c}0.11 \\
(0.34)\end{array}$ & $\begin{array}{l}1.18^{* * * * *} \\
(0.70)\end{array}$ & 0.7632 & 8.0842 & 8.52 & 27.74 & $\begin{array}{c}0.12 \\
(0.23)\end{array}$ & $\begin{array}{l}0.60 * * * * \\
(0.43)\end{array}$ & 1.6527 & 7.9916 & 7.11 & 15.64 \\
\hline Carpel number & $\begin{array}{c}0.38^{*} \\
(0.30)\end{array}$ & $\begin{array}{l}0.88^{* * * * *} \\
(0.62)\end{array}$ & 171.08 & 404.24 & 12.93 & 19.88 & $\begin{array}{c}-0.15 \\
(0.33)\end{array}$ & $\begin{array}{l}1.53^{* * * *} \\
(0.70)\end{array}$ & -67.18 & 680.04 & $\dagger$ & 26.16 \\
\hline Petal length & $\begin{array}{c}-0.14 \\
(0.35)\end{array}$ & $\begin{array}{l}1.28 * * * * \\
(0.90)\end{array}$ & -0.1354 & 1.3224 & $\dagger$ & 16.76 & $\begin{array}{c}0.22 \\
(0.28)\end{array}$ & $\begin{array}{l}0.99 * * * * \\
(0.53)\end{array}$ & 0.3503 & 1.5356 & 5.96 & 12.48 \\
\hline Stamen length & $\begin{array}{c}-\mathbf{0 . 2 5} \\
(0.30)\end{array}$ & $\begin{array}{l}1.25^{* * * * *} \\
(0.70)\end{array}$ & -0.0364 & 0.1976 & $\dagger$ & 26.77 & $\begin{array}{l}\mathbf{0 . 4 4}^{* *} \\
(0.19)\end{array}$ & $\begin{array}{c}\mathbf{0 . 2 8}^{*} \\
(0.24)\end{array}$ & 0.1704 & 0.1061 & 9.07 & 7.16 \\
\hline Pollen number & - & - & - & - & - & - & $\begin{array}{c}0.01 \\
(0.18)\end{array}$ & $\begin{array}{l}1.06^{* * * *} \\
(0.32)\end{array}$ & 56.74 & 4619.43 & 2.19 & 19.74 \\
\hline
\end{tabular}

$N=42$ sires ( 84 dams)

Significance levels for heritabilities are from Anova (see Methods): $* P<0.05 ; * * P<0.01 ; * * * P<0.001 ; * * * P<0.0001$.

Heritabilities that differ significantly between the sex morphs, as determined by randomization tests (see Methods), are in italic for $0.05<P<0.10$ and in bold for $P<0.001$. $\dagger C V$ inestimable because of a nonpositive variance estimate. 
Table 3 Phenotypic (a) and genetic (b) correlations (based on paternal half-sib means) among reproductive traits within each sex morph of Fragaria virginiana, and genetic correlations across the sex morphs

\begin{tabular}{|c|c|c|c|c|c|c|c|c|c|c|}
\hline & \multicolumn{5}{|c|}{ Hermaphrodites } & \multicolumn{5}{|c|}{ Females } \\
\hline & $\begin{array}{l}\text { Flower } \\
\text { biomass }\end{array}$ & $\begin{array}{l}\text { Carpel } \\
\text { number }\end{array}$ & $\begin{array}{l}\text { Petal } \\
\text { length }\end{array}$ & $\begin{array}{l}\text { Stamen } \\
\text { length }\end{array}$ & $\begin{array}{l}\text { Pollen } \\
\text { number }\end{array}$ & $\begin{array}{l}\text { Flower } \\
\text { number }\end{array}$ & $\begin{array}{c}\text { Flower } \\
\text { biomass }\end{array}$ & $\begin{array}{l}\text { Carpel } \\
\text { number }\end{array}$ & $\begin{array}{l}\text { Petal } \\
\text { length }\end{array}$ & $\begin{array}{l}\text { Stamen } \\
\text { length }\end{array}$ \\
\hline \multicolumn{11}{|c|}{ (a) Phenotypic correlations } \\
\hline $\begin{array}{l}\text { Flower number } \\
\text { Flower biomass } \\
\text { Carpel number } \\
\text { Petal length } \\
\text { Stamen length }\end{array}$ & 0.09 & $\begin{array}{l}0.11 * \\
0.42 * * * *\end{array}$ & $\begin{array}{l}0.10 * \\
0.51 * * * * \\
0.02\end{array}$ & $\begin{array}{l}0.07 \\
0.36 * * * * \\
0.03 \\
0.42 * * * *\end{array}$ & $\begin{array}{l}0.06 \\
0.51 * * * * \\
0.22 * * * * \\
0.23 * * * * \\
0.39 * * * *\end{array}$ & & $0.13 *$ & $\begin{array}{l}0.05 \\
0.45 * * * *\end{array}$ & $\begin{array}{l}0.02 \\
0.54 * * * * \\
0.14 * *\end{array}$ & $\begin{array}{l}0.01 \\
0.36 * * * \\
0.08 \# \\
0.49^{* * * *}\end{array}$ \\
\hline \multicolumn{11}{|c|}{ (b) Genetic correlations } \\
\hline Hermaphrodites & & & & & & & & & & \\
\hline Flower number & $\begin{array}{c}-0.15 \\
(0.13)\end{array}$ & $\begin{array}{c}0.06 \\
(0.16)\end{array}$ & $\begin{array}{c}0.10 \\
(0.20)\end{array}$ & $\begin{array}{c}0.15 \\
(0.22)\end{array}$ & $\begin{array}{c}-0.24 \\
(0.12)\end{array}$ & $\begin{array}{l}0.41 * * \\
(0.11)\end{array}$ & $\begin{array}{c}-0.10 \\
(0.16)\end{array}$ & $\begin{array}{c}-0.10 \\
(0.14)\end{array}$ & $\begin{array}{c}-0.21 \\
(0.14)\end{array}$ & $\begin{array}{c}-0.29 \# \\
(0.14)\end{array}$ \\
\hline Flower biomass & & $\begin{array}{l}0.42 * * \\
(0.11)\end{array}$ & $\begin{array}{l}0.39^{* *} \\
(0.14)\end{array}$ & $\begin{array}{c}0.23 \\
(0.15)\end{array}$ & $\begin{array}{l}0.34^{* *} \\
(0.15)\end{array}$ & $\begin{array}{c}0.15 \\
(0.13)\end{array}$ & $\begin{array}{l}0.50 * * \\
(0.09)\end{array}$ & $\begin{array}{c}0.28 \# \\
(0.14)\end{array}$ & $\begin{array}{c}0.24 \\
(0.15)\end{array}$ & $\begin{array}{c}0.19 \\
(0.16)\end{array}$ \\
\hline Carpel number & & & $\begin{array}{c}-0.19 \\
(0.18)\end{array}$ & $\begin{array}{c}-0.12 \\
(0.20)\end{array}$ & $\begin{array}{c}0.15 \\
(0.13)\end{array}$ & $\begin{array}{l}0.11 \\
(0.15)\end{array}$ & $\begin{array}{c}0.28 \# \\
(0.13)\end{array}$ & $\begin{array}{l}0.58 * * * \\
(0.10)\end{array}$ & $\begin{array}{c}-0.10 \\
(0.10)\end{array}$ & $\begin{array}{c}-0.28 \# \\
(0.15)\end{array}$ \\
\hline Petal length & & & & $\begin{array}{l}0.65^{* * *} \\
(0.10)\end{array}$ & $\begin{array}{c}0.24 \\
(0.12)\end{array}$ & $\begin{array}{c}0.05 \\
(0.20)\end{array}$ & $\begin{array}{c}0.23 \\
(0.13)\end{array}$ & $\begin{array}{c}-0.02 \\
(0.12)\end{array}$ & $\begin{array}{l}0.53^{* * * *} \\
(0.16)\end{array}$ & $\begin{array}{l}0.39 * * \\
(0.10)\end{array}$ \\
\hline Stamen length & & & & & $\begin{array}{c}0.34^{*} \\
(0.16)\end{array}$ & $\begin{array}{c}0.09 \\
(0.21)\end{array}$ & $\begin{array}{c}0.19 \\
(0.17)\end{array}$ & $\begin{array}{c}0.12 \\
(0.13)\end{array}$ & $\begin{array}{l}0.41 * * \\
(0.13)\end{array}$ & $\begin{array}{l}0.42 * * \\
(0.10)\end{array}$ \\
\hline Females & & & & & & & & & & \\
\hline Flower number & & & & & & & $\begin{array}{c}0.26 \# \\
(0.20)\end{array}$ & $\begin{array}{c}-0.06 \\
(0.20)\end{array}$ & $\begin{array}{c}0.03 \\
(0.19)\end{array}$ & $\begin{array}{c}0.01 \\
(0.22)\end{array}$ \\
\hline Flower biomass & & & & & & & & $\begin{array}{l}0.57 * * * \\
(0.10)\end{array}$ & $\begin{array}{l}0.53^{* * *} \\
(0.13)\end{array}$ & $\begin{array}{c}0.39^{*} \\
(0.13)\end{array}$ \\
\hline Carpel number & & & & & & & & & $\begin{array}{c}0.15 \\
(0.18)\end{array}$ & $\begin{array}{c}0.07 \\
(0.19)\end{array}$ \\
\hline Petal length & & & & & & & & & & $\begin{array}{l}0.64 * * * \\
(0.10)\end{array}$ \\
\hline
\end{tabular}

Sample sizes for females and hermaphrodites are 486 and 522 for phenotypic correlations (except those with flower biomass which were 381 and 401 ) and 42 for all genetic correlations.

Significance levels: $\# 0.05<P<0.10 ; * P<0.05 ; * * P<0.01 ; * * P<0.001 ; * * * P<0.0001$.

$\infty$ Standard errors for genetic correlations determined by a jackknife resampling procedure.

$\checkmark \quad$ Genetic correlations that differ significantly between the sex morphs, as determined by randomization tests (see Methods), are in italic for $0.05<P<0.10$. 
remain when negative heritabilities are truncated to zero in the randomization tests.

\section{Phenotypic and genetic correlation of floral traits within hermaphrodites and females}

Most floral traits were positively phenotypically correlated in both sex morphs and several floral traits were positively correlated with flower size (Table 3a). Strong genetic correlations were revealed between flower size and several traits, as well as between petal and stamen length in both sex morphs, and between stamen length and pollen production in hermaphrodites (Table $3 b$ ). The regression of phenotypic correlations on genetic ones indicated that there is a strong positive relationship between them, but that phenotypic were larger than genetic correlations in both sex morphs (hermaphrodite: $r_{\mathrm{g}}=1.29 r_{\mathrm{p}}-0.14, r^{2}=0.78, P=0.0001, N=15$; female: $r_{\mathrm{g}}=1.29 r_{\mathrm{p}}-0.09, \quad r^{2}=0.88, \quad P=0.0001$, $N=10)$.

Most traits were genetically correlated in a similar fashion within the sex morphs, except for two pairs of traits (flower number-flower biomass, and petal lengthcarpel number) for which there were intriguing differences in the direction of the correlation. In both cases the genetic correlation was positive in females but negative in hermaphrodites; however, these only reached marginal significance ( $P=0.06,0.09$, respectively).

\section{Genetic correlation of floral traits between hermaphrodites and females}

Genetic correlations between homologous floral traits in the two sex morphs (Table 3b) were all positive, significantly greater than zero, and significantly less than one (all $P<0.01$ ). Correlations between nonhomologous floral traits were mostly not significant, with the exception of positive genetic correlations involving stamen and petal length (Table $3 \mathrm{~b}$ ).

\section{Discussion}

This study has revealed significant genetic variation underlying sexually dimorphic floral traits in F. virginiana. Estimates of narrow-sense heritabilities were generally lower than those for broad-sense heritabilities, suggesting a significant nonadditive genetic contribution to total genetic variance. This nonadditive component could consist of dominance, epistatic or maternal variance (Lynch \& Walsh, 1998); however, the present results can not distinguish among these possibilities. Low narrow-sense heritabilities for carpel, pollen and flower numbers may not be surprising because additive genetic variation is often expected to be low for traits like these that are closely related to fitness (reviewed in Roff, 1997). In fact, low narrow-sense heritabilities are not unusual for primary sexual traits, such as pollen and carpel (ovule) number (e.g. Mazer \& Schick, 1991; Fenster \& Carr, 1997) and flower number (e.g. Elle, 1998; Meagher, 1999).

Despite low narrow-sense heritabilities for floral traits, there were some intriguing differences in heritabilities for three traits shared by the sex morphs. Significant (or marginally significant) dimorphism was found for narrow-sense heritabilities for stamen length, petal length and carpel number. Divergent narrow-sense heritabilities could result from different phenotypic or additive genetic variances, or both. Here, additive genetic variation for carpel number in hermaphrodites was extremely low (sampling error resulted in a negative variance estimate), and not significantly different from zero, but was significant in females, despite equivalent phenotypic variances (Tables 1 and 2). Stamen and petal length, on the other hand, showed significant sexual dimorphism in both phenotypic and genetic variances, with females having lower phenotypic variances and exceedingly low (negative) additive genetic variance estimates which were not significantly different from zero (Tables 1 and 2). Differences in genetic variances between the sexes could be caused by genes that are sexlinked or have sex-limited expression (Eisen \& Legates, 1966; Cowley et al., 1986). Fragaria virginiana does not have dimorphic sex chromosomes, but linkage could still exist between sex-determining loci and those determining stamen length, petal length and carpel number. However, the contribution of sex-linked genes to sexual dimorphism in polygenic characters is generally believed to be small, because the sex chromosomes comprise only a small fraction of the whole genome (Lande, 1980). It is more likely that sex-limited expression of additive genetic variance arises from autosomal genes being expressed differentially in the internal (e.g. hormonal or genetic) environment of the sex morphs (Eisen \& Legates, 1966; Cowley et al., 1986). Moreover, because genes interact via developmental pathways, genes expressed early will have significant consequences for the phenotypic manifestation of those expressed later (Whitlock et al., 1995), and thus epistatic interactions could vary between the sex morphs. In addition, genetic variance dimorphism could arise from differences between the sex morphs in the strength of stabilizing selection, the magnitude of mutational effects (Lande, 1980) and/or the alteration of genetic variation following a bottleneck (Goodnight \& Schwartz, 1997).

Sexual dimorphism in narrow-sense heritability for stamen length might be expected, because stamens are functional in hermaphrodites, but nonfunctional in females (Ashman, in press). Sex-limited expression of 
additive genetic variance for stamen length might result if genes that abolish pollen production in females also limit the expression of genes involved in other developmental features of stamens. Because of the overlap in genes regulating the development of petals and stamens (Coen \& Meyerowitz, 1991) alterations in the stamen pathway may influence petal development as well. Likewise, marginally significant dimorphism in narrow-sense heritability of carpel number could be a consequence of genes that alter carpel function in hermaphrodites. However, because carpel function is not entirely abolished in hermaphrodites, i.e. hermaphrodites still set fruit with viable seeds, although fruit-set can be quite low (Ashman, 1999), sex-limited expression of genetic variation in carpel number may be less pronounced than that seen for stamen length.

We have little information on the prevalence of sexual dimorphism in genetic variance parameters. Even though significant sexual dimorphism in heritabilities has been found in some animal species (e.g. Eisen \& Legates, 1966; Cowley et al., 1986), this is not always the case (e.g. Reeve \& Fairbairn, 1996). In plants, there is some indication of both style morph- (O'Neil \& Schmitt, 1993), and sex morph-based (Meagher, 1999) polymorphism in heritabilities of floral traits, but the significance of these differences has not generally been tested. Because it is important to be able to recognize when differences are spurious, perhaps arising from sampling error (Reeve \& Fairbairn, 1996), or when differences are absent because of large standard errors, testing for sexspecific differences in heritabilities is not a trivial task (Shaw, 1991; J. Lawrence \& T.-L. Ashman, unpubl. $\mathrm{ms}$.). However, if sex-specific variation in heritabilities is widespread then the implication for the evolution of sexual dimorphism is substantial. Specifically, sexual dimorphism can evolve even in the absence of sexdifferential selection (Cheverud et al., 1985), because the sex morph with the higher heritability will have the greater direct response to equivalent selection. Thus, if selection were acting similarly on stamen length in the sex morphs of $F$. virginiana, hermaphrodites would respond whereas females would not, generating greater dimorphism in stamen length. However, selection is actually stronger on stamen length in hermaphrodites than in females (Ashman, unpubl. ms.), leading to selection dimorphism in the same direction as the variance dimorphism. If the genetic correlation for stamen length between the sex morphs is strong and positive (see below), then divergent selection can lead to sexual dimorphism even more rapidly (Cheverud et al., 1985).

Theoretical work has shown that a positive genetic correlation between homologous traits in the sex morphs can constrain independent responses to sex- differential selection when heritabilities are equivalent (Lande, 1980; Cheverud et al., 1985), but that when there is sexual dimorphism in heritabilities such a correlation can facilitate divergence of the sex morphs even in the absence of divergent selection (Cheverud et al., 1985). Here, I found significant positive betweensex correlations for all homologous traits; however, these were also significantly less than 1 . These findings are in line with those found in the few studies in plants (Eckhart, 1993; Lyons et al., 1994; Meagher, 1999). Moderate between-sex genetic correlations, such as those found here, will not have as great a facilitating or constraining effect on sexual dimorphism as high ones (Lande, 1980; Cheverud et al., 1985). However, even a trait like stamen length, which has substantial sexlimited additive genetic effects (in hermaphrodites) could persist for a very long time in females because, despite apparent selective neutrality (Ashman, in press), female stamen length is significantly correlated with several other traits (Table 3b). However, because the magnitude and direction of genetic correlations can vary across environments (Lyons et al., 1994), genetic studies performed in $F$. virginiana's natural habitat are needed before conclusive predictions can be made regarding the level of constraint or facilitation these correlations represent.

In conclusion, the findings of significant sexual dimorphism in phenotypic variances and heritabilities, as well as only moderate between-sex genetic correlations suggest that greater sexual dimorphism could evolve in this population of $F$. virginiana, even if selection is not divergent. However, strong developmental integration of traits (e.g. stamen and petal length) and high levels of nonadditive genetic (or maternal) variance may represent barriers to complete sexual dimorphism. If variance dimorphism, such as that found here, is prevalent in gynodioecious species (or accompanies incipient gynodioecy), then sexual dimorphism in floral traits could evolve faster than previously thought, or might even evolve without differential selection. If the latter is the case, variance dimorphism could represent a nonadaptive explanation for widespread sexual dimorphism in floral traits such as petal size.

\section{Acknowledgements}

Thanks to Heather Arendt, Mike Barron, Prita Gosh, Sue Guers, Nealy Grey, Tara Herman, Dana Hirte, Mike Hitchens, Erica Shepard, Kim Woomer and Ellen York for able and tireless glasshouse assistance; the staff of Pymatuning Laboratory of Ecology for logistic support; to Jeffrey Lawrence for writing the resampling programs; and to Steve Tonsor, Susan Kalisz, Donna Vogler and anonymous reviewers for comments on the 
manuscript. This research was supported by the National Science Foundation (DEB 9508635 and 9707247), and by the University of Pittsburgh's Faculty of Arts and Sciences Research Grant, Central Research Development Fund, and Department of Biological Sciences. This is contribution number 105 to the Pymatuning Laboratory of Ecology.

\section{References}

AHMADI, H. AND BRINGHURST, R. S. 1989. Genetics of sex expression in Fragaria species. Am. J. Bot., 78, 504-514.

ARNOLD, s. 1983. Morphology, performance, and fitness. Am. Zool., 23, 347-361.

ASHMAN, T.-L. 1994. Reproductive allocation in hermaphrodite and female plants of Sidalcea oregana ssp. spicata (Malvaceae) using four currencies. Am. J. Bot., 81, 433-438.

ASHMAN, T.-L. 1999. Determinants of sex allocation in a gynodioecious wild strawberry: implications for the evolution of dioecy and sexual dimorphism. J. Evol. Biol., 12, 648-661.

AShMAN, T.-L. Pollinator selectivity and its implications for the evolution of dioecy and sexual dimorphism. Ecology, 81, in press.

ASHMAN, T.-L. AND HITCHENS, M. S. Dissecting the causes of variation in intra-inflorescence allocation in a sexually polymorphic species, Fragaria virginiana (Rosaceae). Am. $J$. Bot, $\mathbf{8 7}$, in press.

BeLl, G. 1985. On the function of flowers. Proc. R. Soc., 224, 233-265.

BRIDGES, W. C. AND KNAPP, S. J. 1987. Probabilities of negative estimates of genetic variances. Theor. Appl. Gen., 74, 269-274.

BRINGHURST, R. S. 1990. Cytogenetics and evolution in American Fragaria. HortScience, 25, 879-881.

CHEVERUd, J. M., DOw, M. M. AND LEUTENEGGER, w. 1985. The quantitative assessment of phylogenetic constraints in comparative analysis: sexual dimorphism in body weight among primates. Evolution, 39, 1335-1351.

COEN, E. S. AND MEYEROWITZ, E. M. 1991. The war of the whorls: genetic interactions controlling flower development. Nature, 353, 31-37.

CONNER, J. K., RUSH, S., KERCHER, S. AND JENNETTEN, P. 1996. Measurements of natural selection on floral traits in wild radish (Raphanus raphanistrum). II. Selection through lifetime male and female total fitness. Evolution, 50, 1137-1146.

COWLEY, D. E., ATCHLEY, W. R. AND RUTLEDGe, J. J. 1986. Quantitative genetics of Drosophila melanogaster: I. Sexual dimorphism in genetic parameters for wing traits. Genetics, 114, 549-566.

DELPH, L. F., GALlowAy, L. F. AND STANTON, M. L. 1996. Sexual dimorphism in flower size. Am. Nat., 148, 299-320.

ECKHART, v. M. 1993. Do hermaphrodites of gynodioecious Phacelia linearis (Hydrophyllaceae) trade off seed production to attract pollinators? Biol. J. Linn. Soc., 50, 47-63.
EISEN, E. J. AND LEGATES, J. E. 1966. Genotype-sex interaction and the genetic correlation between the sexes for body weight in Mus musculus. Genetics, 54, 611-623.

ELLE, E. 1998. The quantitative genetics of sex allocation in the andromonecious perennial, Solanum carolinense (L.). Heredity, 80, 481-488.

FENSTER, C. B. AND CARR, D. E. 1997. Genetics of sex allocation in Mimulus (Scrophulariaceae). J. Evol. Biol., 10, 641-661.

GOODNIGHT, C. J. AND schwARTZ, J. M. 1997. A bootstrap comparison of genetic covariance matrices. Biometrics, 53, 1026-1039.

HOULE, D. 1992. Comparing evolvability and variability of quantitative traits. Genetics, 130, 195-204.

LANDE, R. 1980. Sexual dimorphism, sexual selection and adaptation in polygenic characters. Evolution, 34, 292-305.

LYNCH, M. AND WALSH, B. 1998. Genetics and Analysis of Quantitative Traits. Sinauer Associates, Sunderland, MA.

LYONS, E. E., MILlER, D. AND MEAGHER, T. R. 1994. Evolutionary dynamics of sex ratio and gender dimorphism in Silene latifolia: I. Environmental effects. J. Hered., 85, 196-203.

MAZER, S. AND SCHICK, C. T. 1991. Constancy of population parameters for life history traits in Raphanus sativus L. I. Norms of reaction and the nature of genotype by environment interactions. Heredity, 67, 143-156.

MEAGHER, T. R. 1999. The quantitative genetics of sexual dimorphism. In: Geber, M. A., Dawson, T. E. and Delph, L. F. (eds) Gender and Sexual Dimorphism in Flowering Plants, pp. 275-290. Springer, Berlin.

MORGAN, M. T. 1992. The evolution of traits influencing male and female fertility in outcrossing plants. Am. Nat, 139, 1022-1051.

O'NEIL, P. AND SCHMITT, J. 1993. Genetic constraints on the independent evolution of male and female reproductive characters in the tristylous plant Lythrum salicaria. Evolution, 47, 1457-1471.

REEVE, J. P. AND FAIRBAIRN, D. J. 1996. Sexual size dimorphism as a correlated response to selection on body size: an empirical test of the quantitative genetic model. Evolution, 50, 1927-38.

ROFF, D. A. 1997. Evolutionary Quantitative Genetics. Chapman \& Hall, New York.

SAS, 1989. SAS/STAT User's Guide, version 6, 4th edn, vol. 1. SAS Institute Inc., Cary, NC.

SHAw, R. G. 1991. The comparison of quantitative genetic parameters between populations. Evolution, 45, 143-151.

STAUDT, G. 1989. The species of Fragaria, their taxonomic and geographical distribution. Acta Hortic., 265, 23-33.

VALLEAU, W. D. 1923. The inheritance of flower types and fertility in the strawberry. Am. J. Bot., 10, 259-274.

WHITLOCK, M.C., PHILLIPS, P. C., MOORE, F. B.-G. AND TONSOR, S. J. 1995. Multiple fitness peaks and epistasis. Ann. Rev. Ecol. Syst., 26, 601-629. 